\title{
Comparative effectiveness of angiotensin-converting- enzyme inhibitors: Is an ACE always an ace?
}

\author{
Adrian F. Hernandez MD MHS, Robert A. Harrington MD
}

$\infty \quad$ See related article page $\mathrm{I} 303$

A lthough large randomized clinical trials remain the foundation for informing evidence-based prescribing, vast data sources can provide insight into complex questions that arise in clinical decision-making. Using tens of thousands to millions of patients, registries and administrative databases now serve as the "living textbooks" envisioned more than 40 years ago. ${ }^{1}$ Common clinical questions can now be readily addressed because of the marked advances in clinical data informatics and the application of information technology to clinical care. As an example of this wealth of data, in this issue of CMAJ, Pilote and colleagues ${ }^{2}$ use administrative databases of hospital discharges and prescription claims to study the comparative effectiveness of angiotensin-converting-enzyme (ACE) inhibitors in the treatment of congestive heart failure.

The value of renin-angiotensin-aldosterone inhibition in reducing mortality and morbidity among patients with heart failure and left ventricular systolic dysfunction has been well established in multiple large randomized clinical trials. ${ }^{3,4}$ With evidence indicating about a $25 \%$ decrease in mortality and a $35 \%$ decrease in mortality or admission to hospital, ACE inhibitors are used universally in the treatment of heart failure in a broad range of patients. ${ }^{4}$ Over the last several decades, our understanding of ACE inhibition has evolved from a theory based on simple hemodynamic effects of vasodilatation to beneficial effects on mechanisms throughout the cardiorenal and cardiovascular systems. ${ }^{5}$

\section{Are all ACE inhibitors the same?}

Given the important effects of ACE inhibitors on clinical outcomes, as shown in clinical trials, we need to know whether there are differences among the large number of ACE inhibitors currently being marketed (II in the United States and I2 in Canada). ACE inhibitors differ in their molecular structure, potency, bioavailability, plasma half-life and tissue affinity. The patient populations in which they have been studied in randomized clinical trials also differ (Table I). For example, some researchers have proposed differentiating among ACE inhibitors based on tissue binding and suggest that blood pressure correlates better with tissue ACE levels than with circulating ACE, which could relate to improved outcomes. ${ }^{17}$

ACE inhibitors have not been studied uniformly in patients with heart failure and left ventricular dysfunction. Indeed

\section{Key points}

- Every day, clinicians choose drugs from classes of therapy to treat many conditions. To determine which drug is best, researchers often perform observational studies comparing the efficacy of drugs.

- There may be critical differences in outcomes among groups of ACE inhibitors commonly used to manage heart failure, but further studies comparing their efficacy are needed to validate this finding.

- Moving forward, physicians, payers, professional societies and government agencies should invest in large, practical trials to answer these important questions.

there are no large clinical trials comparing the efficacy of one ACE inhibitor with another to determine which one best improves survival. Once the early ACE inhibitors were shown to be beneficial, the later studies compared them mainly with other vasodilators; comparisons with more specific angiotensin-receptor blockers occurred later. Unfortunately, because patents on ACE inhibitors ended, the incentives for funding head-to-head trials of ACE inhibitors never materialized. Instead, manufacturers chose to gain market share by looking for previously unstudied indications or by focusing on advertising rather than on comparative studies. In addition, initial regulatory approval of a new ACE inhibitor required only that the new agent be shown to be "safe and effective."

However, there are some lessons to be learned from ACE inhibitor studies. The results of successful trials, particularly the Heart Outcomes Prevention Evaluation (HOPE) trial, ${ }^{13}$ led many physicians to believe that class effect was so powerful that any ACE inhibitor would be beneficial in any of the indications that had been studied with specific individual agents. The failure of the Prevention of Events with Angiotensin Converting Enzyme Inhibition (PEACE) trial ${ }^{16}$ challenged this concept of class effect; however, some argued that differences

The authors are with the Duke Clinical Research Institute and the Division of Cardiovascular Medicine, Department of Medicine, Duke University School of Medicine, Durham, NC

Une version française de cet article est disponible à l'adresse www.cmaj.ca/cgi/content/full/I78/Io/I3I6/DCI 
in the patient population or other treatments could explain the lack of benefit.

Earlier work from Pilote and colleagues also suggests that ACE inhibitors may not have a class effect. ${ }^{18}$ Similar to the current analysis, the previous study analyzed data from an administrative database, and the results suggested that ramipril was associated with lower mortality compared with most other ACE inhibitors. At the time, both the study and the accompanying commentary ${ }^{19}$ noted the limitations of administrative databases and the potential for unknown confounding. Simply stated, were the observed benefits attributable to the drug or to some other aspect of care or characteristic that occurred more often when prescribing ramipril? In followup, Hansen and colleagues ${ }^{20}$ published an observational analysis of ACE inhibitors involving more than $\mathrm{I} 6000 \mathrm{pa}-$ tients who had myocardial infarction. They found no differences in mortality between ramipril and other ACE inhibitors, including captopril and enalapril.

\section{What does the new evidence show us?}

The present study by Pilote and colleagues ${ }^{2}$ uses administrative data from 3 Canadian provinces to examine the relation between prescription of different ACE inhibitors and longterm mortality after admission to hospital because of heart failure. The authors took special steps to minimize bias by restricting the population to patients with a first admission because of heart failure. They also tried to eliminate potential confounding by performing careful regression modelling, and by attempting to account for differences in demographics, clinical characteristics (based on claims) and more limited physician and hospital characteristics. Their study involved more than 40000 patients and looked at the use of 8 different ACE inhibitors over a follow-up period of more than 3 years. Drug-specific sample sizes varied from more than I4 000 patients who received ramipril to 490 patients who received cilazapril. After detailed risk adjustment, their results

Table 1: Example characteristics of select angiotensin-converting-enzyme (ACE) inhibitors

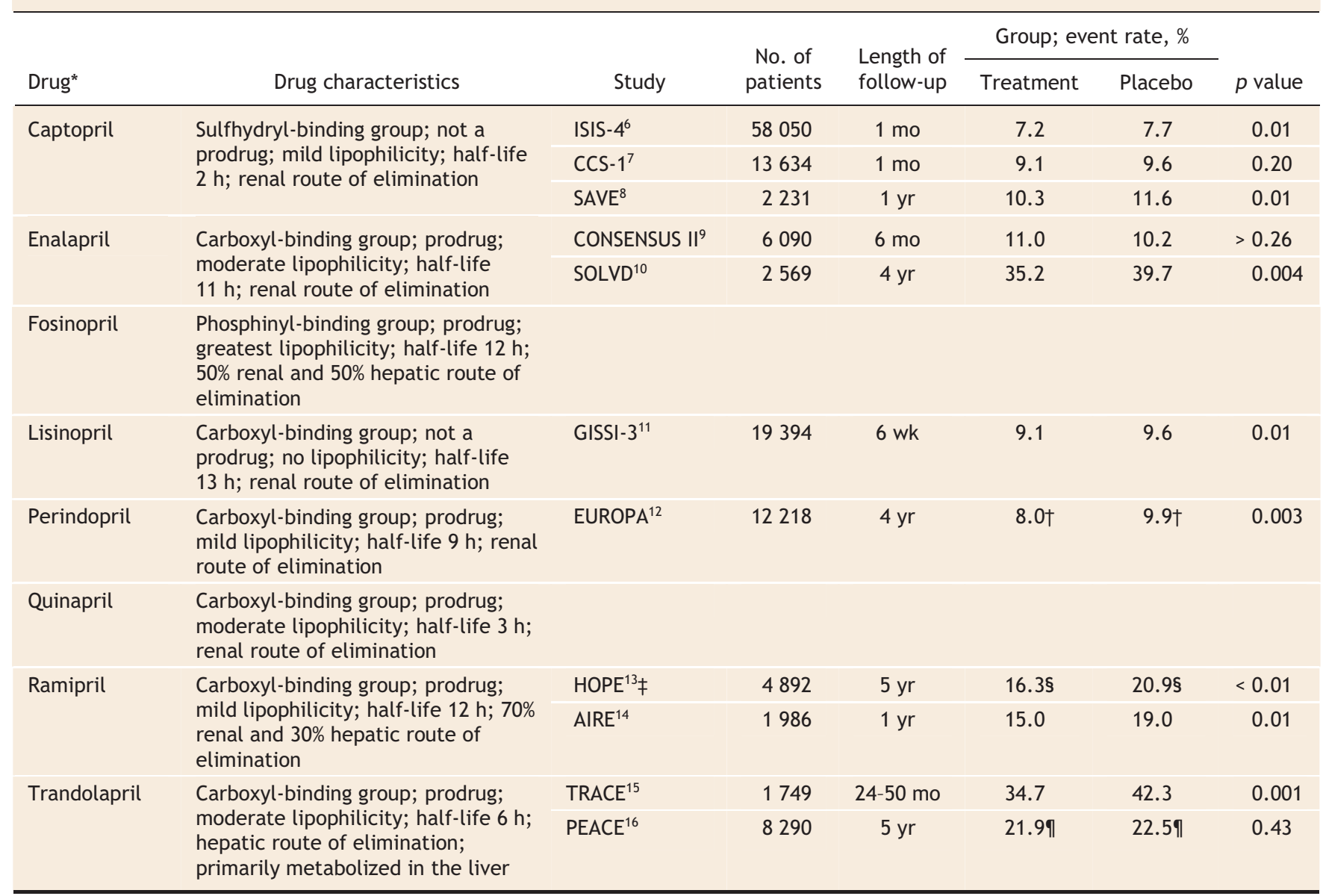

Note: AIRE = Acute Infarction Ramipril Efficacy study; CCS-1 = Chinese Cardiac Study; CONSENSUS II = Cooperative New Scandinavian Enalapril Survival Study II; EUROPA

= European Trial on Reduction of Cardiac Events with Perindopril in Patients With Stable Coronary Artery Disease; GISSI-3 = Gruppo Italiano per lo Studio della

Sopravvivenza nell'Infarto Miocardico; HOPE = Heart Outcomes Prevention Evaluation; ISIS-4 = Fourth International Study of Infarct Survival; PEACE = Prevention of

Events with Angiotensin Converting Enzyme Inhibition; SAVE = Survival and Ventricular Enlargement trial; SOLVD = Studies of Left Ventricular Dysfunction; TRACE =

Trandolapril Cardiac Evaluation study.

*The order of the list is not preferred usage for the treatment of congestive heart failure.

†Comparative outcome of cardiovascular mortality, myocardial infarction or cardiac arrest.

fOnly study patients with a history of acute myocardial infarction are included in the data.

§Comparative outcome of death, myocardial infarction or stroke.

१Comparative outcome of cardiovascular mortality, myocardial infarction or coronary revascularization. 
suggest that ramipril is clinically similar to other ACE inhibitors except for enalapril and captopril, which were associated with higher mortality. The adjusted hazard ratio for death (and 95\% confidence interval) was I.Io (I.04-I.I6) for enalapril and I.I3 (I.OI-I.26) for captopril.

As with any observational study that predominantly uses administrative data, there are 2 potential interpretations. First, the results are valid because confounding and bias have been limited and, based on known data, the hypothesis is biologically and clinically plausible. The alternative explanation is that residual confounding and bias remain and can never be adequately adjusted, despite careful analytical technique, because of limitations inherent to the administrative databases.

Unlike large clinical trials in which randomization balances both the known (measured) and unknown (unmeasured) differences among groups, in the analysis of treatment comparisons using nonrandomized data we must rely on appropriate adjustment for known confounders and restriction of population cohorts to limit bias. Although it is certainly conceivable that ramipril may be superior to other ACE inhibitors based on characteristics of the drug and on prior analyses, there are some important potential sources of error that cannot be fully addressed by the methods used by Pilote and colleagues.

First, prescription patterns may vary significantly between an ACE inhibitor popularized by the HOPE trial and ACE inhibitors traditionally used to treat heart failure. That is, ramipril may be prescribed more readily to lower-risk patients who fit HOPE-like criteria, whereas other ACE inhibitors may be prescribed more readily to higher-risk patients similar to those enrolled in the trials that originally assessed the efficacy of those drugs. Second, physicians' prescribing habits of ramipril may be related to other care activities (e.g., cardiovascular procedures, other medications) that influence beneficial outcomes, not necessarily to the effects of ramipril. ${ }^{21}$ Third, additional patient characteristics may differ among various study populations; however, because data were unavailable (i.e., not collected) they could not be used in the adjustment models.

In the study by Pilote and colleagues, ejection fraction appears to be the most prominent missing characteristic. Beyond being one of the most important risk factors in establishing prognosis among patients with heart failure, left ventricular dysfunction also establishes true eligibility for an ACE inhibitor based on professional guidelines and measures of quality-of-care performance. Furthermore, ejection fraction would help further limit bias by restricting the population to patients with left ventricular dysfunction, among whom the benefit of ACE inhibition is already known. Thus, these limitations, especially the potential differential use of ACE inhibitors based on knowledge of the ejection fraction, could be the fatal flaw of their analysis.

\section{The way forward}

The study by Pilote and colleagues suggests that there may be critical differences in outcomes among the groups of ACE inhibitors commonly used to manage heart failure. However, because of the limitations of the study, it will be imperative to validate the findings in another data set that can address these limitations, especially the knowledge of ejection fraction. As Pilote and colleagues note, it is unlikely that a large randomized clinical trial would be conducted to test this hypothesis of differential ACE inhibitor effects in an area as important as heart failure with millions of lives at stake. A largescale, practical clinical trial may be appropriate to define the single best or best combination of renin-angiotensinaldosterone inhibitors. ${ }^{22}$ However, our current system of clinical research is inadequate in permitting the rapid incorporation of simple questions such as this into mainstream practice. Thus, the critical issue is how best to organize trials that address common public health questions and that require large sample sizes to appropriately and adequately test the hypotheses generated from comparative effectiveness studies. ${ }^{22}$ Reform in this arena is desperately needed. ${ }^{23}$

Although the number of comparative effectiveness studies will likely continue to grow - especially when payers make choices about whether to list therapies on formularies based on their cost-effectiveness - we hope much more can be done. At the very least, professional societies and government agencies should continue to guide improvement in methodologies and standards for reporting results in comparative effectiveness studies. However, the stakes are too large to risk so many lives without conducting the large, practical clinical trials that can establish more definitive evidence in support of the best therapy. All stakeholders, including clinicians, should demand reinvention of the clinical research enterprise to fund and conduct large, practical clinical trials. Moving forward, practical clinical trials will be the best way to know which agent is the true "ace" and to deliver the best care possible.

Competing interests: Adrian Hernandez has received speaker fees from Novartis. Robert Harrington has received consulting fees from the Annenberg Center for Health Sciences, AstraZeneca, Baxter, Bayer AG, Bristol Myers Squibb, Indigo Pharmaceuticals, NicOx, OLG Research, Sanofi-Aventis, Schering-Plough Corporation, Seredigm and WebMD/theheart.org; received speaker fees from the Schering-Plough Corporation; and received honoraria or other compensation for research related to the article from AstraZeneca, Bristol Myers Squibb, CanAm Bioresearch, Johnson \& Johnson, KAI Pharmaceuticals, Medicure, Merk Group, Millennium Pharmaceuticals, Novartis AG Group, Pfizer, Schering-Plough Corporation and The Medicines Company.

Contributors: Both of the authors contributed to the conception and design of the manuscript, drafted and revised the article and approved the final version for publication.

\section{REFERENCES}

I. Stead EA Jr. The way of the future. Trans Assoc Am Physicians 1972;85:1-5

2. Pilote L, Abrahamowicz M, Eisenberg M, et al. Effect of different angiotensinconverting-enzyme inhibitors on mortality among elderly patients with congestive heart failure. CMAJ 2008;178:I303-II.

3. Flather MD, Yusuf S, Kober L, et al. Long-term ACE-inhibitor therapy in patients with heart failure or left-ventricular dysfunction: a systematic overview of data from individual patients. ACE-Inhibitor Myocardial Infarction Collaborative Group. Lancet 2000;355:1575-8I.

4. Garg R, Yusuf S. Overview of randomized trials of angiotensin-converting enzyme inhibitors on mortality and morbidity in patients with heart failure. Collaborative Group on ACE Inhibitor Trials. JAMA I995;273:1450-6.

5. Khalil ME, Basher AW, Brown EJ Jr, et al. A remarkable medical story: benefits of angiotensin-converting enzyme inhibitors in cardiac patients. J Am Coll Cardiol 200I; 37:1757-64.

6. ISIS-4 (Fourth International Study of Infarct Survival) Collaborative Group. ISIS-4: a randomised factorial trial assessing early oral captopril, oral mononitrate, and 
intravenous magnesium sulphate in 58 o5o patients with suspected acute myocardial infarction. Lancet 1995;345:669-85.

7. Oral captopril versus placebo among 13,634 patients with suspected acute myocardial infarction: interim report from the Chinese Cardiac Study (CCS-I). Lancet I995;345:686-7.

8. Pfeffer MA, Braunwald E, Moyé LA, et al. Effect of captopril on mortality and morbidity in patients with left-ventricular dysfunction after myocardial-infarction results of the Survival and Ventricular Enlargement Trial. N Engl J Med I992;327: 669-77.

9. Swedberg K, Held P, Kjekshus J, et al. Effects of the early administration of enalapril on mortality in patients with acute myocardial infarction. Results of the Cooperative New Scandinavian Enalapril Survival Study II (CONSENSUS II). $N$ Engl J Med I992;327:678-84.

Io. The SOLVD Investigators. Effect of enalapril on survival in patients with reduced left ventricular ejection fractions and congestive heart failure. $N$ Engl J Med ig9I; 325:293-302.

II. Gruppo Italiano per lo Studio della Sopravvivenza nell'Infarto Miocardico. GISSI3: effects of lisinopril and transdermal glyceryl trinitrate singly and together on 6week mortality and ventricular function after acute myocardial infarction. Lancet I994;343:III5-22.

I2. European Trial on Reduction of Cardiac Events with Perindopril in Stable Coronary Artery Disease Investigators. Efficacy of perindopril in reduction of cardiovascular events among patients with stable coronary artery disease: randomised, double-blind, placebo-controlled, multicentre trial (the EUROPA study). Lancet 2003;362:782-8.

I3. Heart Outcomes Prevention Evaluation Study Investigators. Effects of an angiotensin-converting-enzyme inhibitor, ramipril, on cardiovascular events in high-risk patients. N Engl J Med 2000;342:145-53.

I4. Acute Infarction Ramipril Efficacy (AIRE) Study investigators. Effect of ramipril on mortality and morbidity of survivors of acute myocardial infarction with clinical evidence of heart failure. Lancet I993;342:82I-8.

I5. Kober L, Torp-Pedersen C, Carlsen JE, et al. A clinical trial of the angiotensinconverting-enzyme inhibitor trandolapril in patients with left ventricular dysfunction after myocardial infarction. Trandolapril Cardiac Evaluation Study Group. $N$ Engl J Med I995;333:1670-6.

I6. Braunwald E, Domanski MJ, Fowler SE, et al. Angiotensin-converting-enzyme inhibition in stable coronary artery disease. N Engl J Med 2004;351:2058-68.

I7. Brown NJ, Vaughan DE. Angiotensin-converting enzyme inhibitors. Circulation I998;97:I4II-20.

I8. Pilote L, Abrahamowicz M, Rodrigues E, et al. Mortality rates in elderly patients who take different angiotensin-converting enzyme inhibitors after acute myocardial infarction: A class effect? Ann Intern Med 2004;I4I:IO2-I2.

I9. Hennessy S, Kimmel SE. Is improved survival a class effect of angiotensinconverting enzyme inhibitors? Ann Intern Med 2004; I4I:157-8.

20. Hansen ML, Gislason GH, Kober L, et al. Different angiotensin-converting enzym inhibitors have similar clinical efficacy after myocardial infarction. BrJ Clin Pharmacol 2008;65:217-23

2I. DeLong E. Hierarchical modeling: its time has come. Am Heart J 2003;145:I6-8.

22. Tunis SR, Stryer DB, Clancy CM. Practical clinical trials: increasing the value of clinical research for decision making in clinical and health policy. JAMA 2003; 290:I624-32.

23. US Food and Drug Administration. FDA and Duke launch public-private partnership to modernize clinical trials. Rockville (MD): The Administration; 2007. Available: www.fda.gov/oc/initiatives/criticalpath/partnership.html (accessed 2008 Mar 3).

Correspondence to: Dr. Adrian F. Hernandez, Duke Clinical

Research Institute, PO Box 17969, Durham NC 27715, USA; fax 919668-7063; adrian.hernandez@duke.edu 